\title{
Creating gameful experience in the object-oriented programming classroom: A case study
}

\author{
Mathupayas Thongmak, Thammasat Business School, Thammasat University, \\ mathupayas@tbs.tu.ac.th
}

\begin{abstract}
Gamification has become popular in education. However, gamified classroom activity together with assessment activity are not yet much explored. In this study, the gamification was tested by assigning students enrolling in a programming concept class (object-oriented programming using Java) to play a simple card game and contest their programs involving the card game with others. The simple card games are chosen to decrease an instructor's burden. The results of the focus group discussions show that gamified classroom activity could enhance students' problem solving skills, engagement, attention to the course content, enjoyment and friendship, understanding, and creativity. The gamified assessment activity also lets students have more time to solve problems, clearly understanding the problems, increasing their confidence, decrease recitation, and reduce their stress. Intrinsic motivation is the main construct driving students to engage in gamification, supported by students' extrinsic motivation.
\end{abstract}

Keywords: Gamification, object-oriented programming, education, case study, classroom, and assessment activity.

\section{Introduction}

Programmer shortage has been growing for years (Liyanagunawardena, Lundqvist, Micallef, \& Williams, 2014). Thailand is one of countries facing the software developer shortage at the present time (Singsungnoen \& Piriyasurawong, 2016). Programming is one of the foundations of information systems (Marshall, Cardon, \& Godin, 2014). It is also a core course for many computer-related majors, especially a computer science major and a software engineering major. However, most students have experiences in computer programming learning difficulties, compared to other courses (Azmi, Iahad, \& Ahmad, 2015; Bosse \& Gerosa, 2017; Combefis, Bersnevicius, \& Dagiene, 2016; Özmen \& Altun, 2014; Qu, Zhao, Wang, \& Liu, 2014). In addition, it was previously documented that there are high dropout rates and high failure rates in programming courses (Bosse \& Gerosa, 2017; Combefis et al., 2016). Reasons of failures consist of personal problems, problems in class activities, and problems in the programming process (Özmen \& Altun, 2014). Students face difficulties and frustration in programming knowledge, programming skills, understanding the semantics and structures, as well as debugging respectively (Azmi et al., 2015; Özmen \& Altun, 2014). Object-oriented programming (OOP) is widely adopted by education and industry, but it is one of the greatest challenges for most students (Azmi et al., 2015; Combefis et al., 2016). Conventional teaching and learning practices frequently face difficulties in maintaining students' motivation and engagement (Fotaris, 
Mastoras, Leinfellner, \& Rosunally, 2016). Programming courses should be taught with the active involvement of students (Azmi et al., 2015).

Active learning is about engaging learners in the learning process, allowing them to talk, listen, read, write, and reflect the course content through activities such as problem-solving exercise, simulations, role-playing activities, and so on. Knowledge construction could also be accomplished through the active learning elements in three main stages: underpinning, ownership, and engaging. The active learning elements are designed to the course activities by the instructors (Koohang, Paliszkiewicz, Klein, \& Nord, 2016). Gamification could be applied to the engaging stage of active learning to make students actively and collaboratively engage when constructing new knowledge. Introducing young participants to programming in a fun and norisk environment could develop their interests and skills to become programmers (Liyanagunawardena et al., 2014). Embedding gamification in the programming courses could enhance students' participation and positively impact their learning (Combefis et al., 2016; Liyanagunawardena et al., 2014). Gamification is the use of game mechanics to encourage desired behaviors of the target group, in non-game environments such as education, government, manufacturing, health care, and military (Kim, 2013; Li, Dong, Untch, \& Chasteen, 2013). It can help successfully transfer the different levels of knowledge at the different stages (Yurov, Beasley, Kwak, \& Floyd, 2014). A game-based multi-touch learning environment was applied to support understanding and practicing the core mathematical concepts (Schäfer et al., 2013). Gamification is also applied in online/social learning to promote students' interaction and participation (Combefis et al., 2016; Li et al., 2013; Simões, Redondo, \& Vilas, 2013). The application of gamification in a computer game development, effectively increases students' understanding and engagement, while positively impacts course marks and lecture attendance (O'Donovan, Gain, \& Marais, 2013). Moreover, applying gamification to a course in the master level significantly increases class attendance and online participation (Barata, Gama, Jorge, \& Gonçalves, 2013). Using serious games in a short course on promotion of entrepreneurship for electronic engineering students leads to more engagement, interest towards the course, as well as students' competencies and entrepreneurship skills (Bellotti et al., 2013).

Nevin et al. (2014) developed a web-based software applying gamification principles to assess the acceptance and use of medical knowledge competition among internal medicine residents. Results showed that leaderboards were the most important motivator for the residents. Iosup and Epema (2014) applied social gaming elements to teach undergraduate and graduate courses. They found a correlation between the percentage of passing students and the participation in activities as well as assignments. Attali and Arieli-Attali (2015) examined the effects of point, an element of gamification, on students' performance in basic mathematic concepts. The higher likeability rating was received in the first session and higher perceived effort were obtained from eighth grade students. Krause, Mogalle, Pohl, and Williams (2015) explored the application of social game elements in Massive Open Online Courses (MOOCs). Their results showed the significant increase of students' retention and learning success in terms of average test scores. Baxter, Holderness, and Wood (2016) improved training experiences for employees using gamification. Their results revealed the higher trainee satisfaction and knowledge gain than the traditional training method. Alhammad and Moreno (2018) conducted a systematic meta-analysis mapping of gamification to the software engineering field to identify research gaps and 
opportunities for future studies. Their systematic meta-analysis mapping classified and analyzed 29 primary studies according to four factors: their software process area, used gamification elements, research methods, and published forum types. Findings indicated that most of them focused on software development area and used simple game elements such as points and badges. In sum, existing research in this field was quite preliminary and more research to explore the gamification's influence on software engineering is needed. El Tantawi, Sadaf, and AlHumaid (2018) explored first-year dental students' satisfaction with gamification and its impact on the improvement of academic writing. Pre- and post-assessments of students' academic writing skills were collected. Overall satisfaction of students with gamification and their perception of skill improvement were modest. However, the improvement of students in their actual writing skills was very high. Kanbul and Ozdamli (2018) examined the attitudes and opinions of students about applying gamification supported flipped classroom in the Project Development course, using both quantitative and qualitative methods. Results showed that most of students satisfied with gamified activities. Their motivation and in-class competition were also increased.

Although some studies have investigated the gamification in the education context, the empirical research on the gamification's benefits, impacts, and effectiveness is scarce (Akpolat \& Slany, 2014; Attali \& Arieli-Attali, 2015; Hanus \& Fox, 2015; Kankanhalli, Taher, Cavusoglu, \& Kim, 2012). It is time consuming to implement a gamified classroom (Villagrasa \& Duran, 2013). Educators have to carefully design and effectively implement gamification to obtain its benefits and to successfully engage students in the learning process (Yurov et al., 2014). Moreover, it is unclear whether the motivation to engage in gamified activities is extrinsic or intrinsic (Barata et al., 2013). Teaching and assessment of programming classes are considered to be difficult and ineffective, resulting in unpleasing outcomes such as disengaging, cheating, and dropping out (Fotaris et al., 2016). Therefore, this study tries to achieve four research objectives: 1) to explore the impacts of applying a simple game in the object-oriented programming classroom on students' perceived usefulness and engagement, 2) to understand the effects of gamified assessment activities, which are related to the simple game, 3) to investigate main motivation driving students to engage in the gamified activities, and 4) to guide educators on simple, but effective, gamification methods for OOP classes.

\section{Background}

\section{Gamification: Game Elements}

As mentioned earlier, gamification is using game mechanics in non-game environments (de Sousa Borges, Durelli, Reis, \& Isotani, 2014). Recommended game mechanics to be used in educational materials consist of a collection, points, leaderboards, levels, status, feedback, achievements, and epic meaning (González \& Area, 2013). Iosup and Epema identify seven core tools for gamification. Three core mechanics are: 1) point systems, 2) level, access, and power, as well as 3) leaderboards. Four dynamics are badges, onboarding, social engagement loops, and unlocking content (Iosup \& Epema, 2014). Bunchball (2010), also agreed by Simões et al. (2013), defined game elements as consisting of: points, levels, trophies/ badges/ achievements, virtual goods, leaderboards, and virtual gifts; and game dynamics: reward, status, achievement, 
self-expression, competition, and altruism. Gamification design of collaborative storytelling websites should contain three components: achievement, interpersonal relationship, and role playing. Achievement has four design factors: status, reputation, goal seeking, and reward. Interpersonal relationship has three design factors: altruism, competition, and instruction. Roleplaying has three design factors: time pressure, self-expression, and group identification. These design factors are later developed into design features (gamification features) (Hsu, Chang, \& Lee, 2013). A preliminary taxonomy of gamification elements is listed, comprising of four main groups that are generally framing, social features, intrinsic incentives, and extrinsic incentives (Robinson \& Bellotti, 2013). Accomplishment-based reward system implemented by gamification are: points/stars/badges, progress bars, and leaderboards. Other elements are the storyline and visual elements, goals, and rewards (O'Donovan et al., 2013). Basic gamification mechanics applied in the study of Krause et al. (2015) are: achievements/badges, score points, leaderboards, avatars, and time limit. These elements are not required to be a central system, but should be contained in the system to motivate users. For example, foursquare awards users who are checking in with points or badges (de Sousa Borges et al., 2014).

\section{Gamifying the Programming Practices}

Akpolat and Slany (2014) applied game thinking as well as game mechanics with the software development process in teams of 10 students each. The classroom project and the output from students were increased after applying gamification. Ibanez, Di Serio, and Delgado Kloos (2014) assessed the effectiveness and engagement of the gamified learning activity in the $\mathrm{C}$ programming course, using mixed method (logs, questionnaires, \& pre- and post-tests). The results revealed the positive effects on the students' engagement and a moderate learning improvement. Snipes, Nair, and Murphy-Hill (2014) added the game-like feedback to the software development environment, to help software developers learn and improve their practices. Findings indicated that most developers were interested in gamification, resulting in the adjustment of their practices when receiving points or charts feedback. Fotaris, Mastoras, Leinfellner, and Rosunally (2015) conducted a quasi-experimental study adapting a real time sequence of scored quizzes, instructor feedback, and live coding to introduce an interactive learning experience for students in a Python programming course. Findings showed the satisfactory outcomes in terms of attendance, downloading of course material, and final grades. Gebremichael (2016) examined the benefits of using gamification to develop an assessment tool for evaluating students' knowledge of Python programming (the programming \& algorithm module). The game could assess students' learning effectively. All students liked the game and enjoyed the assessment process. Gamification provided various benefits such as the improvement of written test performance.

\section{Methodology}

\section{Gamifying Classroom and Assessment Method}

The games in this study took place at the Thammasat Business School, Thammasat University during the second semester of the 2014 academic year and the first semester of the 2015 academic year. Students from both semesters were introduced to simple card games in the 
second or third week after the opening of the semester. Simple card games were applied because they had educative property, letting players to be aware of, understand, master, and achieve the learning goals easier (González \& Area, 2013). In previous studies, there were application of card games for gamification such as Gamicards (Ferro, Walz, \& Greuter, 2014). For each week, students were randomly assigned to play as individuals and teams. They were playing a total of 10 rounds in five weeks, which were five rounds as individuals and five rounds as teams. After the second or the third week of play, they were informed that the games would later be modified and turn into the midterm exams.

For the first group, two-person card game was applied. Each student had 10 cards. Each card contained a number, ranging from one to 10. Then, both players selected one card and showed to their opponents. The person who selected a card with the higher number would win. The result of each time of play could be a win, lose, or draw. In each round, all players had to play 10 times. Total win times were calculated to find the winner for that round. Players could also switch a card at a random with their opponent once. For the second group, two-person card game was employed. The first player started with six cards with numbers from one to 10 . The first player selected two cards to be a card with the hidden number and a blind card and faced those cards down on the table. Then, the second player had to guess the hidden number several times, using the first player's replies (less than or more than or blind/ no answer). If the second player could get the correct answer (hidden number) within three guesses, he/ she would win. If not, the first player would win. In each round, all players had to play six times.

According to the game mechanics and elements to engage students (González \& Area, 2013; Kankanhalli et al., 2012; Iosup \& Epema, 2014; O'Donovan et al., 2013; Simões et al., 2013; Villagrasa \& Duran, 2013), visual elements (cards), allow different routes to success (choosing to switch a card or selecting his/her own blind card), points (winning scores, accumulated winning points), comparisons and classifications (classifying players as winner or loser groups), feedback (the announcement of results to peers), and social engagement loops/collaboration (inclass interactions between groups of students using team play) were adopted in the gamified classroom for both groups.

At the midterm period, games in the classroom were slightly modified to be the take-home exams. Take-home tests were applied because they could increase student knowledge, produce longer retention of course materials, and reduce students' anxiety (Rich, Colon, Mines, \& Jivers, 2014). However, cheating could be a potential problem (Tao \& Li, 2012). Therefore, the gamified assessment activities were separated into two phases as follows. For the first phase of submission, students had to submit the flowchart describing their programs' logics and algorithms together with all source code (.java) and executable files (.class). All submitted programs had to remain unchanged after the first submission. After that, in the second phase of submission, an instructor would give students the opponent matching and the competition rules to run programs. Students had to submit results of competition back to the instructor immediately within a day after the instructions released. Students had no ideas about each other's algorithm before. Students were not allowed to modify their programs at this phase. Finally, the exam scores came from three parts, which were: 1) the description of their own algorithms both in the flowchart and the source code comments, showing students' clear understanding of their 
programs, 2) the shortest lines of code compared to others, solving the same problems with better logic, and 3) the competition results, which were verified in pairs with others' results and the programs from the first submission. In the future, video recording when students were coding should be added to be as another means to prevent cheating. The focus group discussions were conducted after the exam scores were announced.

\section{Study Design, Data Collection, Analysis, and Validation}

A criterion-based sampling was applied to choose participants that meet the determined criteria (Özmen \& Altun, 2014). The study groups were undergraduate students who were exposed to similar experiences, taking the gamified object-oriented programming course, at Thammasat Business School, Thammasat University. Two focus groups were conducted with a total of 13 students from two consecutive semesters in the same course. All students participated in the class as game players and team players and passed the test related to the game. Groups ranged in size from six to seven students each and games lasted from 27 to 32 minutes. Focus groups are qualitative methods to describe the phenomena being investigated. They allow a researcher to extract individuals' subjective attitudes and experiences, which are normally inaccessible. The researcher could also probe data by participants' interactions with one another and explore the shared importance (Breen, 2006; Dollar \& Merrigan, 2002; Mediani, Nurhidayah, Mardhiyah, \& Panigoro, 2017). A practical guide to focus-group research involved in conducting focus-group research was applied (Breen, 2006). The focus groups were held within two weeks after treatment (gamified classroom and gamified assessment activity). All students joined the focus group interviews willingly because they had no effects on students' marks. Voluntary students were invited to join a free pizza party with an instructor. The audio clips of focus group discussions were recorded during lunchtime on round tables at the open and relaxed place near the faculty, with the permission of participants. Interview questions were designed to cover the research objectives. Informed-consent procedures were explained at the beginning of each focus group interview. Questions and discussion topics were started with the opening question, introductory questions, transition questions, key questions, and ending questions (Breen, 2006). They were as follows:

- Name, age, place, field of study, and students' past programming experiences.

- Gaming experiences, frequency of playing games, preferred game types, and player types according to (Bartle, 2004; Iosup \& Epema, 2014; Zichermann \& Linder, 2010).

- Preference role in game playing.

- Opinions on gamified classroom.

- Opinions on gamified assessment activities, compared to traditional assessment methods. (Traditional assessment methods are writing source codes in the papers or taking exams in the computer lab or answering general examination questions.)

- Suggestions for improving gamified classroom and gamified assessment activities.

- Motivations to engage gamified classroom and gamified assessment activities.

The recordings of focus group interviews were transcribed through three phases of analysis: a preliminary analysis to get a general sense of data, a detailed analysis to separate data into segments, and a conclusion phase to categorize topics and label key findings. Data from all focus 
groups were analyzed together to determine the inter-connectedness between topics. The level of agreement or disagreement between participants and the frequency of opinions was also considered (Breen, 2006). The participants' anonymity was protected in this paper, using a male/ female student to hide his/her identity. Theory triangulation was applied to validate information and conclusions using multiple theories and perspectives to interpret and describe the data (Johnson, 1997).

\section{Findings}

\section{Participants' Profiles}

The first focus group had seven participants, with three female students and four male students in the 20-to 22-year age range. Five of them were sophomore students, and two of them were senior students. Four of them studied in the Faculty of Commerce and Accountancy (two students from Management Information Systems (MIS) major, one student from Accounting major, and one student from Finance major), one of them studied in the Faculty of Economics, one student came from the Faculty of Liberal Arts (Library and Information Science major), and one student studied in the Faculty of Science and Technology (Statistics major). Regarding their programming experiences, four students had never studied programming before. One female student had ever studied programming from e-learning websites such as codeacademy. Two senior students had some experiences in programming. One of them passed two $\mathrm{C}++$ courses, another one is familiar with Visual Basic (VB) and QBasic. The second focus group had six participants, with one female student and five male students in the 19-to 20-year age range. Two of them were junior students, four of them were sophomore students. All students studied in the Faculty of Commerce and Accountancy (two students from Accounting major and four students from MIS major). Two of them had slight experiences in programming in high school. Four of them had some experiences with $\mathrm{C}$ and JavaScript. One of them used to join a programing competition. Another one used to program a robot in junior high school.

\section{Gaming Experience and Player Types}

In the first focus group, three students heavily played games such as the Sim, puzzle game, simple mobile games, multiplayer game (League of Legends). One student played various games two times per week. A student played puzzle games e.g. Line: Disney Tsum Tsum three to four times per month. A student slightly played games such as Need for Speed, Crossword once within three to four months. One student normally did not play games. In the second group, two students played games in leisure time such as Counter-Strike, Harvest Moon, and role-playing or turn-based strategy game on a computer. Some students played computer games such as hard stone, blood haze, massively multiplayer online role-playing game (MMORPG), and multiplayer online battle arena (MOBA) games. The findings were in line with the previous work that children and adolescents such as students spent their leisure time on playing games (Akpolat \& Slany, 2014; Chen, Kuo, Chang, \& Heh, 2009).

There were four types of game players consisting of achievers, socializers, explorers, and killers (Bartle, 2004; Iosup \& Epema, 2014; Zichermann \& Linder, 2010). Two students from the first focus group believed that they were achievers. Achievers liked to acquire points/ status, enjoyed 
the playing process, and wanted to play well. They also liked to share game joys and defeat others (Bartle, 2004; Iosup \& Epema, 2014; Zichermann \& Linder, 2010). The rest of them were explorers who took pleasure in game playing activities and elements (Bartle, 2004; Iosup \& Epema, 2014; Zichermann \& Linder, 2010). A student also emphasized that she was an explorer, not a killer player type, because she liked to explore other ways to win. A student in the second group said she was the killer type who did not like long game playing. Killers loved competition and hanker for only the victory (Bartle, 2004; Iosup \& Epema, 2014; Zichermann \& Linder, 2010). One student classified himself as an achiever. He leisurely collected points for the relaxation purpose. Two students thought that they were both achievers and explorers, depending on the game types. A student supported that the player types relied on the game types. Another student also defined himself as both achievers (for MMORPG games) and the killers (for MOBA games).

\section{Students' Perspectives}

Analysis of the focus group interviews showed a number of key findings related to students' viewpoints on gamified classroom and gamified assessment activities, future game suggestions for gamified classroom and gamified assessment, and students' motivation to engage gamification, as shown in Figure 1.

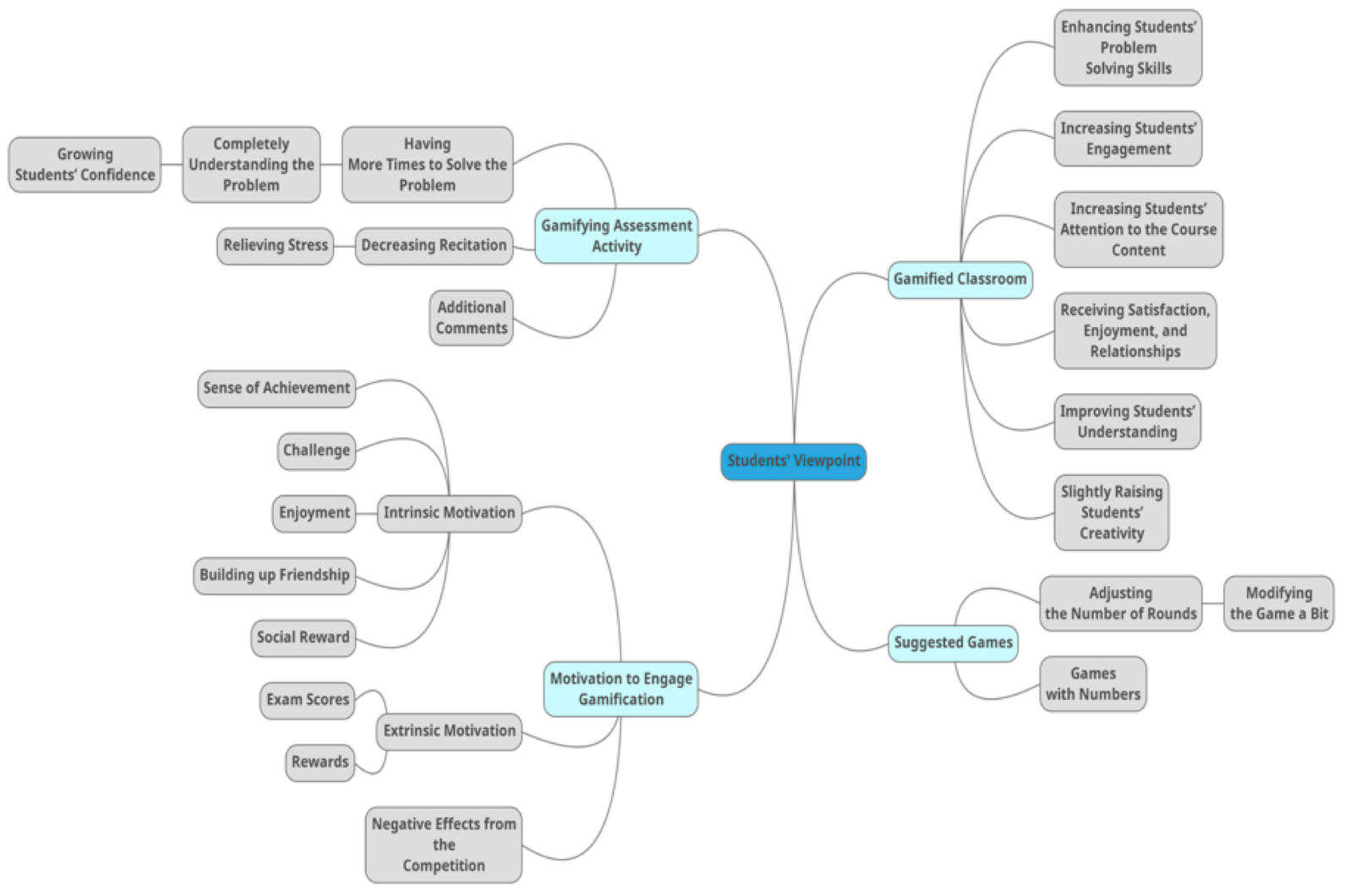

Figure 1. The Holistic View of Findings 


\section{Students' Viewpoints on Gamified Classroom}

In terms of the roles students in the first focus group wanting to be in the game playing, two students preferred sole game playing or preferred to be followers. A male student wanted to be a single player or a leader. One student also did not like team play, preferring to play alone. Another female student liked to play with the team, but wanted to cooperate with the team, rather than being a team leader. Two female students would evaluate the performance of team leader first. If the team leader performed well, they chose to be good supporters. For the second group, many students generally wanted to be team leaders. The finding was supported by the significant of a hypothesis that game leadership in a team play group was higher than that of an individual play group (Jang \& Ryu, 2011). They considered the performance of leader before choosing their roles too. Two of them wanted to be followers because of easiness and anxiousness that leaders had to have the initiative and charisma. The results were in line with educational playability properties in terms of learnability, which means the player's capacity to understand and master the game system and mechanics (González \& Area, 2013). When playing as a team with real-life friends, players normally gave an importance to trust and respect-oriented factor of game leadership (Jang \& Ryu, 2011).

Participants were asked to share their opinions of the gamified classroom in terms of understanding, problem solving, creativity, attention to the course content, and engagement. They were also asked to share what they received from playing games in the classroom in terms of enjoyment, content coverage, and relationships with classmates. An analysis of focus group data revealed 4 key findings, consisting of 1) enhancing students' problem solving skills 2) increasing students' engagement 3) increasing students' attention to the course content 4) satisfaction, enjoyment and relationships received from the gamified classroom 5) improving students' understanding and 6) slightly raising students' creativity.

\section{Key Finding 1: Enhancing Students' Problem Solving Skills}

Three female students in the first group alleged that their problem solving skills enhanced. First student said that she had to generate ideas and increased her problem solving skills. She had to understand each player's style because they played differently. Opponents were changed every round, so she had to change her strategies too. Two students supported her: "Yes, yes. When I met new opponent, I had no time to think much. But after seeing an opponent's card, I had to decide to play a card from my hand. It helped in solving problems. Strategies from this play could also apply to the next play", "I had to make a decision based on available information (cards in my hands). Asking myself that how to solve the problem. Problem solving skills were increased". Logic is a method of reasoning. Three students in the second group mentioned about their problem solving skills in terms of logic development. A student said that playing games in the classroom could develop students' logic, more than any other aspects. A male student also said that "In the earliest stage, I did not know what I should add. But when I played for a while, I know the logic was here. I could add some logic to this part." Another student supported him:

"The main point was that the game was not only play for fun, but it developed logic. Like others said, when playing for a while, you may know that this opponent would choose this card. So, I could decide what card (number) I should 
choose next, developing my logic and guiding how to change from the logic to program."

A female student also said:

"Algorithms or strategies were developed every time we played. The second or the third round were better than the first round, suitable for the development of teaching and learning. But I was not sure about the content coverage. I knew only that I had to repeat many iterations to solve problems."

However, two students emphasized that turning logics into programs required the basic ideas or fundamental knowledge regarding programming concepts. Findings harmonized with the study that stated that game pulled students in a process of deep learning to find a solution of the problem (Vos, Van Der Meijden, \& Denessen, 2011). Game-like project potentially motivated students to practice their problem solving skills (Thamvichai \& Supanakorn-Davila, 2012). Moreover, the challenges received from games could expand players' capacities (Hamari et al., 2016).

\section{Key Finding 2: Increasing Students' Engagement}

Playing games in the class could increase students' engagement. In the first group, four students really wanted to join the game. Two students felt challenged because he/ she was curious to know whether he/ she would win this round or next round or not. Three male students felt neutral about playing games in the classroom. But one of them said: "When playing games, people knew each other more. Helping each other in the group was fun, sometimes it was stressful (Laugh)." In the second focus group, a student said that when comparing between lectures and play games, games were more interesting than lectures, making them wanted to attend class or to join games more. In terms of class attendance, some students said they normally attended the class, although without gamification. Other students in both classes did not mention about class attendance. Findings conformed to the evidence from the previous study that gamification improves students' engagement (Barata et al., 2013; O'Donovan et al., 2013), which was positively associated with perceived learning (Hamari et al., 2016). Game-like designed training also enhanced trainees' engagement (Yang, Asaad, \& Dwivedi, 2017). Challenges made a game addictive (O'Donovan et al., 2013). The higher challenges increased the game engagement or sense of immersion (Hamari et al., 2016). The game challenges could increase motivations. Lack of challenges could lead to disengagement (Hamari et al., 2016). Gamification could increase retention and learning success. Social game elements significantly extended students' retention gain (Krause et al., 2015). Contests made the programming course more attractive for students (Combefis et al., 2016).

\section{Key Finding 3: Increasing Students'Attention to the Course Content}

A male student from the first focus group said that gamified classroom increased his attention to the course content because it was linked to the examination questions. Paying attention to the game could help him to perform well on the upcoming exam. A female student from the second group said:

"If the game in the classroom guided the examination, it encouraged me a lot since I had never written any program. The game guided me to take something 
from the gamified classroom back and turn it into a strategy for next time. It was good."

The results tallied with the study of Gilboy, Heinerichs, and Pazzaglia (2015) that the use of active learning in class let students learn how to use materials more effectively than lecture alone. In addition, when a student was answering a take-home exam, s/he would often review the textbook and notes more frequently than while preparing for the traditional exam (Rich Jr et al., 2014). Game challenges could also motivate users to explore the IS in details (Thiebes, Lins, \& Basten, 2014). Students engaged themselves with more challenging topics (Akpolat \& Slany, 2014). Gamified learning could increase the number of material downloads and enabled students spending more time working for the course (Barata et al., 2013).

\section{Key Finding 4: Receiving Satisfaction, Enjoyment, and Relationships}

All students from the first focus group confirmed that gamified classroom was good. A female student from the first focus group felt relaxed and fun so much to join the game in class. A female student from the second group said: "This game was fun." The results were in line with educational playability properties in terms of emotion, which refers to the player's involuntary impulse in response to the stimulus of the game that induces feelings, and in terms of socialization that is the set of game attributes, elements, and resources promoting the social dimension of the game experience in a group scenario (González \& Area, 2013). Satisfaction would also come when students were allowed to practice newly acquired knowledge or skills (Kim \& Lee, 2012). Instructors should apply playing-and-learning quizzes and other creative approaches to enhance more fun and interest in students' learning processes (Lee, 2010). Fun and enjoyment were important aspects in a multiplayer game, driven by competition, collaboration, and cooperation (Schäfer et al., 2013). Gamification could cause the perceived enjoyment higher (Koivisto \& Hamari, 2014). It could improve learning by increasing enjoyment, playfulness, and fun in boring settings and tedious tasks (Baxter et al., 2016; Hanus \& Fox, 2015).

Regarding relationships with peers, one student mentioned that games made us talking to each other more. The finding was supported by the increase of students - instructor interactions and student-centered learning environments that could enhance students' learning (Schultz, Duffield, Rasmussen, \& Wageman, 2014). Social influence played a vital role in engaging new users in gamification (Koivisto \& Hamari, 2014) Gamified class was effective for increasing the level of class communication (Kim, 2013). Social-feature elements such as relationships and interaction modes were an important part of gamification (Robinson \& Bellotti, 2013).

\section{Key Finding 5: Improving Students' Understanding}

Gamifying classroom could improve students' understanding. Many students from the first group raised hands to support the influence of gamified classroom on their understanding. A female student in the first group specified that gamified classroom affects her understanding. The result was consistent with Kim (2013)'s study that gamification enhanced students' understanding (O'Donovan et al., 2013). Gamified class was more effective than traditional class for improving the level of understanding (Kim, 2013). Individuals participating in gamified training also showed greater knowledge acquisition than others who received non-gamified training (Baxter et al., 2016). Literature studies showed that trainees learning through video-gaming tools had higher knowledge and retention, compared to the control group (Yurov et al., 2014). 


\section{Key Finding 6: Slightly Raising Students’ Creativity}

Two students from the first focus group said that gamified classroom indirectly related to creativity. A male student from the second group said that the logic was added on top, increasing creativity.

\section{Students' Viewpoints on Gamifying Assessment Activity}

Participants were asked to give their opinions on gamified assessment activities, compared to traditional assessment methods, in terms of confidence, understanding, problem solving, creativity, attention to the course content, and engagement. An analysis of focus group data presented three key themes, consisting of 1) having more times to solve the problem, completely understanding the problem, and growing students' confidence 2) decreasing recitation and relieving stress and 3 ) additional comments relating to the gamified assessment.

Key Finding 1: Having More Times to Solve the Problem, Completely Understanding the Problem, and Growing Students' Confidence

All students in the first focus group and three students in the second focus group preferred take home exams over traditional exams. The rest did not give comments. Five students from the first focus group and one student from the second group mentioned that they had more times to think or to solve problems. Another student expressed: "I liked the take-home exam because I had enough times to think." The findings were supported that scores on knowledge items were significantly greater on take-home exams because of additional times that students gained to look up the answers (Rich et al., 2014).

Two students from the first focus group said that they could see the exam's overview. A student said the gamified assessment activities helped him to find the answer easier because he saw the exam's overview (in advance). Therefore, he could think how to solve the problem and whether he could solve that problem or not. He could also do a process of trial and error. Another female student expressed: "Gamified assessment activities let us think and try many options. The game was good, showing us the whole picture of the exam and what were outputs that we needed." A female student in the first focus group gave an example: "I used a normal array at first, but I had more time to improve it later. I thought that I could not do like this in the exam room." A male student from the second group said:

"If I played the game, then applied it with exams later. It seemed like the real work, playing in the real processes. Thus, we knew the logic and processes before turning all of these into a program. On the contrary, if I had never joined the process, I had to think from zero, which was harder. Even though it was common for programming, we should understand the workflow before writing it."

The findings were supported by the evidence from the previous study that gamification improves students' understanding (O'Donovan et al., 2013). Game-like instructions could be useful to enhance students' motivation to learn (Thamvichai \& Supanakorn-Davila, 2012). By playing games, children confronted with problems and had to overcome them by trial and errors, learning from their mistakes and efforts and developing students' problem solving and thinking skills 
(Vos et al., 2011). Two students in the second focus group mentioned about the increase of confidence. A female student voiced her opinion:

"I gained more confidence. I could create more solutions because of having more times. I could repeat my learning. Playing in the first round, I thought that this solution was good. But for the second round, this solution was maybe not the best. In the third round, the solution had to be improved again."

Another male student supported as follows:

"It made me having more confidence. I went back to writing this program at home since the first week. I was familiar with the playing process, so it was easy to write a flowchart, which was easily turned to be a program later."

The results were consistent with the increase of self-sufficiency regarding the solving problems of students when adapting the active learning approach such as a flipped classroom (Aş1ksoy \& Özdaml1, 2016). A flow experience in games could bring a feeling of competence or self-efficacy (Kankanhalli et al., 2012). Students would have greater motivation when they had greater selfefficacy and self-worth. The perception of their competence also related to students' perceived chances of success (Hamari et al., 2016). Higher self-efficacy impacted the continue usage intention (Bhattacherjee, Perols, \& Sanford, 2008). Take-home exams could produce longer retention of material than traditional exams (Rich et al., 2014). Gamification also had a significant effect on course marks (O'Donovan et al., 2013). Game-based mobile apps could help K-12 students to achieve required knowledge: factual knowledge and conceptual knowledge, and enhance their problem-solving skills (Yurov et al., 2014).

\section{Key Finding 2: Decreasing Recitation and Relieving Stress}

A student from the first group said: "It was good to apply games and take-home exam in this course because it decreased stressful in the exam room and I did not have to memorize everything to write the codes too." One student supported that he liked the take-home exam because he was not required to remember everything. The result complied with the literature that gamified classroom was effectively reducing students' stress level (Kim, 2013). In addition, take-home tests helped to increase student knowledge about the information that would be covered in class by providing a base of pre-existing knowledge. It could also reduce test anxiety, drive students to work collaboratively, and elicit their study practices to a deeper level (Rich et al., 2014).

\section{Key Finding 3: Additional Comments Relating to the Gamified Assessment}

An unexpected finding was the comments about the competition in the take-home exam. Five students in the first focus group liked the take-home exam with gamification, but did not like the competition, a part of the exam. A student said the complicated logic was not always given the best results. Therefore, he chose some random numbers by his experience instead, which did not show his actual programming capability. One female student also gave the reason: "I also disliked the competition because I wrote a code with complex algorithms like him, but I may lose to a friend who sequentially picked the numbers from an array, using very simple logic." After 
the instructor asked them that would it be better if the algorithmic complexity was the major part in test score, all students agreed with the change of gamified assessment method.

\section{Suggested Games for Gamifying the Programming Class}

Participants were opened to suggest games or give more comments to improve the gamified programming class. An analysis of focus group data showed 2 key suggestions, consisting of 1) adjusting the number of rounds or modifying the game a bit and 2) games with numbers.

\section{Key Finding 1: Adjusting the Number of Rounds or Modifying the Game a Bit}

A male student from the first focus group suggested that the total competition rounds (in the exam) should be increased from 10 to 30 rounds and more numbers (cards) should be added. Another student disagreed with him:

"This game was good, but it had too much competition rounds. The 10 turns were too much and too difficult to write code for the exam. Five turns would be more suitable for the exam. The 10 turns for playing games in the class were OK."

In the second focus group, two students all agreed with the increase of competition rounds with each opponent, to decrease the influence of luck in the exam's competition. The findings were supported by the previous study stating the balance between the game's difficulties and players' skills was a critical factor for engagement (Tomaselli, Sanchez, \& Brown, 2015).

To modify the old games for future use, a student from the first focus group still emphasized as follows: "I did not want instructor to give importance on the competition much, but I wanted you to give more scores on the technical part." A student in the first group did not like the minus score of the exam competition. The result was consistent with the fact that losing a competition could create a negative impact on students' satisfaction and enjoyment, which were key elements to motivate students' engagement in the gamified tasks (Sepehr \& Head, 2013). Another student in the second group suggested that more numbers (cards) should be added such as using 40 cards instead of 10 cards with 10 numbers because it would make the logic to solve the problem harder. The findings were supported by the previous study stating that successful games were designed to be challenging (Barata et al., 2013). Games stimulated curiosity and interests by creating meaningful learning activities in the contexts which learners were in control (Vos et al., 2011). Games should create a feeling of arousal and control and avoid anxiety and boredom for users (Tomaselli et al., 2015). The control dimension affected the engagement (Chen et al., 2009; Tomaselli et al., 2015). Gamified activities should be adapted and changed to ensure continued gamification benefits (Thiebes et al., 2014).

\section{Key Finding 2: Games with Numbers}

A student in the first focus group proposed the 'Guess a number' game. The game rules were a student selected a number from 0 to 100 . Then, another student guessed the number via multiple attempts. S/he would be hinted by the replies from the first student: for example, the guess number was less than or greater than the correct answer. A female student emphasized that the game had to apply the programming concepts from the class, such as using for loop and operators. She proposed a minesweeper-like game, guessing ordered pair numbers in the table. She suggested that an instructor could ask the suggestion about interesting games from students 
too. The results were in line with educational playability properties in terms of effectiveness, which is offering players a new experience -fun and learning - while they achieve the game's various objectives and reach the final goal (González \& Area, 2013). Educational games should be aligned with the course content (El-Masri, Tarhini, Hassouna, \& Elyas, 2015). Another student proposed the 'Tic-Tac-Toe' game. A male student from the second focus group proposed the 'Guess the numbers' game. The game rules were a student selected a five-digit secret number, formed with digits from zero to nine. Each digit appeared once at most. The set of digits would be guessed many times by another student, using some hints from the first student's reply. Every time, the first student would reply that what digits you guessed were in the correct positions. Suggested games harmonized with the study specifying that the competition was still a major factor to foster players' involvement (Tomaselli et al., 2015).

\section{Students' Motivation to Engage Gamification}

Motivation was one of playability design patterns to facilitate the design of educational games (González \& Area, 2013). Participants were asked to answer what are their motivations to engage gamified classroom and gamified assessment activities. An analysis of focus group data revealed three key findings, consisting of 1) intrinsic motivation in terms of sense of achievement, challenge, enjoyment, building up friendship, and social reward 2) extrinsic motivation in terms of exam scores and rewards, and 3) negative effects from the competition.

\section{Key Finding 1: Intrinsic Motivation in terms of Sense of Achievement, Challenge, Enjoyment, Building up Friendship, and Social Reward}

A student from the first group said: "The motivation was that everything were done by students themselves, such as writing codes, playing games, competing with others, testing programs, and getting scores. Doing everything by myself made me proud. The return was worth." Another female student in the same group said: "I wanted to solve the problems. I wanted to win always. I tried to write the code that matched my ideas most." A male student in the second group wanted to overcome his weakness rather than focusing on the test scores:

"I thought that I wanted my logic being the best. However, every algorithm had a weakness, but I tried to get rid of my weakness. For instance, if I competed with a person, I defeated him often. But when I competed with another person, I frequently won. I tried to find the algorithm that made me win or lose every person equally instead."

Another male student wanted to win, but did not take the exam seriously. Two male students from the second group were curious about what other friends think. One of them also wanted to learn logics, and how to overcome friends in the competition. Another one did not focus on the logic much. Findings accorded with the study of Thamvichai and Supanakorn-Davila (2012), which specified that the game-like project would help enhancing students' learning experiences. Achievement, social, and immersion dimensions could drive players to participate in online games (Kankanhalli et al., 2012). Esteem needs (self-esteem, achievement, mastery, independence, status, dominance, prestige, managerial responsibility) could be fulfilled by the gamified class (Kim, 2013). Contests in programming let students comparing their abilities and learned from others, developing algorithmic problem solving (Combefis et al., 2016). 
Comparisons with peers such as leaderboards could affect students' performance (Hanus \& Fox, 2015). Students in the gamified course frequently compared themselves to peers over time (Hanus \& Fox, 2015).

A male student from the first focus group talked about the novelty of the game: "I consulted all friends. My friends were interested in the game, but they could not help me solve the problem." Another female student supported the interests and challenges of games. Findings complied to the curiosity, challenge, and intrinsic interest pertaining to engagement (Tomaselli et al., 2015). Gamification could drive students to work beyond the learning requirements of the course (Ibanez et al., 2014). Challenges in a game drove the intrinsic pleasure of the players (O'Donovan et al., 2013). The challenges of overcoming the game and mastering it were matters the most to players in all game types (Tomaselli et al., 2015). Challenges were the major behavior drivers in the experience of gamified course (Barata et al., 2013) and economic exchanges such as e-commerce sites (Hamari, Koivisto, \& Sarsa, 2014). Flows captured the peak experiences of intrinsic motivation. They occurred when involving in the challenge tasks (Kankanhalli et al., 2012; Lee, 2010; Sepehr \& Head, 2013).

Two students from the second focus group talked about the game's enjoyment. A female student said:

"It was fun to communicate with other people. I felt good to play the game and talked to junior students. I was serious about the exam only when going back home to think about the logic, but not when playing the games in the class."

The result supported by the fun and learning experiences that should be received from playability properties of educational games (González \& Area, 2013). The challenge activities with playfully satisfying players' basic needs to feel competent were important (Tomaselli et al., 2015). Serious and educational games should combine the challenging activities and the enjoyment experiences to maximize the utilization of players' skills (Hamari et al., 2016). Gamified method could increase participation among students in traditional classrooms (Azmi et al., 2015). Interpersonal relationship was one of design components that should have in gamification designs (Hsu et al., 2013). Gamified class was effective for satisfying social needs in terms of (belongingness and love, work group, family, affection, relationships) (Kim, 2013; Koivisto \& Hamari, 2014).

A female student form the first group mentioned values evaluated by others, praise from peers: "The competition should be focused on the interests of algorithms or the best algorithms, judging by the instructor or ranking by friends." The result was consistent with the importance of interpersonal motivation in learning, which was created by the competition (Chen et al., 2009). Intrinsic incentives such as curiosity, challenge, entertainment, social reward, personal returns, and societal returns should be added into gamification (Robinson \& Bellotti, 2013). Students showed higher levels of intrinsic motivation in the game-based environment (Vos et al., 2011).

\section{Key Finding 2: Extrinsic Motivation in terms of Exam Scores and Rewards}

A female student from the first group said that using exam scores to motivate students were OK. But the instructor had to give less weight on the competition and avoided the zero-sum game. 
Another male student in the first group wanted some rewards instead. A male student from the second group engaged in the gamified classroom because he expected that it would be turned into an exam in the future. The findings were in line with the research report that points slightly affected the test's likeability and perceived efforts of middle school students (Attali \& ArieliAttali, 2015). Adding to record of achievements was one of extrinsic incentives, which should be applied to gamification (Robinson \& Bellotti, 2013). When rewards were presented, a person may be motivated to complete the task (Hanus \& Fox, 2015). However, tangible rewards had a substantial undermining influence on the intrinsic motivation to learn (Barik, Murphy-Hill, \& Zimmermann, 2016; Hanus \& Fox, 2015).

\section{Key Finding 3: Negative Effects from the Competition}

Regarding unexpected findings, a male student from the first group said that he felt pressured when the games in class was adopted to be the exam. A female students in the first focus group said that the competition only without weighting the algorithmic complexity could discourage students. The result could be explained that the students got the lowest scores in the gamified exams. The combination of high challenge but low skill of students could create an anxiety psychological state (Hamari et al., 2016).

In addition to students' perspectives, their learning performance between students in two gamified sections (gamified classroom activity with gamified assessment activity) and students in another two traditional sections (traditional classroom lectures with traditional assessment activity) were compared. An independent samples t-test indicated that there was no significant difference in the midterm scores of students from the gamified classes (Mean $=30.40, S D=$ 4.77 ) and the midterm scores of students from the traditional classes (Mean $=27.57, S D=6.89)$, $t(22)=1.187, p=.248$.

\section{Recommendations}

\section{Student Learning}

Reasons of failures in programming consist of personal problems, problems in class activities, and problem in the programming process (Özmen \& Altun, 2014). Although the gamified classroom together with gamified assessment does not directly improve students' learning performance. Based on students' viewpoints, gamified classroom with a simple game could enhance students' problem solving skills, increase students' engagement in the class, improve students' attention to the course materials, enhance students' relationships in the class, their perceived enjoyment, and satisfaction, develop students' understanding, and slightly raise students' creativity. A simple game could apply to other programming classes to reduce time and costs. Time, cost, level of student readiness, level of instructor readiness, and alignment with the course structure are barriers of the educational game adoption by instructors (El-Masri et al., 2015). In addition, applying simple games with simple rules could overcome two barrier factors that are level of student readiness and level of instructor readiness because of the games' easiness (El-Masri et al., 2015). 


\section{Student Motivation}

Although exam scores or tangible rewards could draw students' attention to the gamified classroom and the gamified assessment, most students are motivated by their intrinsic motivation. The intrinsic motivation consists of a sense of achievement, challenge, enjoyment, building up friendship, and social reward. Both extrinsic and intrinsic motivation should be balanced to promote gamified education (Bellotti et al., 2013). There are three types of students. Student A is highly motivated and interact more with gamification settings. Student B needs more explanation about the perceived benefits of gamifications, whereas student $\mathrm{C}$ does not prefer new lecture form (Akpolat \& Slany, 2014). Therefore, gamifying the assessment method should be done after the careful consideration of the students' types and their performance because some negative effects from the competition in the gamified assessment such as pressure or discouragement could happen to the low-skill students. The novelties of this research are the use of simple offline games (card games) together with gamifying assessment activity in a programming class as the in-class gamified activities and then turning these games to the gamified assessment and exploring students' perspectives in various viewpoints to show their opinions in terms of gamified classroom and gamified assessment activity. Thus, the gamified assessments used in this study narrow the gap in the application of gamification.

\section{Game and Program Design}

The game rules should be modified a little and turned into the gamified take-home exams later. Gamified take-home tests could reduce students' anxiety. Take-home exam also produce longer retention of material than in-class examinations because of student preparation to submit the take-home test (Rich et al., 2014). However, the exam submission processes should be deliberately designed with some protections, such as video recording when students were coding should be added to prevent cheating. The gamified assessment method, the take-home exam relating to the game in class, provides various benefits for students, which are having more time to solve the problem, clearly understanding the problem, and enhancing students' confidence. It also decreases students' recitation and relieves their personal problems in terms of stress or anxiety in programming. Nevertheless, students emphasize that an instructor should give more weight on the algorithmic complexity in the exam scores more than the contest results. They suggest that an instructor could modify the previous games such as adding more numbers (cards), decreasing or increasing the rounds of competition or introduce new simple games with numbers.

\section{Conclusion, Limitations, and Future Works}

The purposes of this study are exploring the effects of using simple games together with gamifying assessment activity in the object-oriented programming course on students' adoption and engagement, revealing the consequence of gamifying assessment activities, examining motivation that drives students' engagement in gamification, and recommending the guideline for the gamified object-oriented programming course. Creating online games or implementing gamification on top of e-learning could be a burden for instructors and may be hard to turn it into take-home exams later. Therefore, this study applies simple card games to reduce time and costs 
to prepare gamified classroom for instructors. Focus group interviews are conducted with students who enroll in a gamified programming concepts course using Java. Theoretical contribution of this study is showing the effects of gamified classroom activities and gamified assessment activities. Factors from the research results could be further applied to develop the conceptual framework for gamification. Some aspects such as positive or negative emotions received from the gamified activities could be explored deeper. Managerial implications of the findings are described in the Recommendations section.

For the research limitations, only two focus groups were interviewed because of the small number of students enrolling in the programming course for each semester. Results based on small samples are difficult to generalize. For future research, gamified classroom and gamified assessment method should be adopted in different environments such as different faculties, different programming languages, or different countries. Furthermore, a quantitative study could be conducted to gain profound understanding of the results of gamified classroom activities and gamified assessment activities as well as generalizing the results. Moreover, the negative effects from gamification could be explored to properly suggest the situation where the gamification should be applied.

\section{References}

Akpolat, B. S., \& Slany, W. (2014). Enhancing software engineering student team engagement in a high-intensity extreme programming course using gamification. Proceedings of the IEEE 27th Conference on Software Engineering Education and Training, 149-153.

Alhammad, M. M., \& Moreno, A. M. (2018). Gamification in software engineering education: A systematic mapping. Journal of Systems and Software, 141, 131-150.

Aşıksoy, G., \& Özdamlı, F. (2016). Flipped classroom adapted to the ARCS model of motivation and applied to a physics course. Eurasia Journal of Mathematics, Science \& Technology Education, 12(6), 1589-1603.

Attali, Y., \& Arieli-Attali, M. (2015). Gamification in assessment: Do points affect test performance? Computers \& Education, 83, 57-63.

Azmi, S., Iahad, N. A., \& Ahmad, N. (2015). Gamification in online collaborative learning for programming courses: A literature review. ARPN Journal of Engineering and Applied Sciences, 10(23), 1-3.

Barata, G., Gama, S., Jorge, J., \& Gonçalves, D. (2013). Engaging engeneering students with gamification. Proceedings of the 5th International Conference on Games and Virtual Worlds for Serious Applications, 1-8.

Barik, T., Murphy-Hill, E., \& Zimmermann, T. (2016). A perspective on blending programming environments and games: Beyond points, badges, and leaderboards. Proceedings of the 2016 IEEE Symposium on Visual Languages and Human-Centric Computing, 134-142.

Bartle, R. A. (2004). Designing virtual worlds. Berkeley: CA: New Riders. 
Baxter, R. J., Holderness Jr, D. K., \& Wood, D. A. (2016). Applying basic gamification techniques to IT compliance training: Evidence from the lab and field. Journal of Information Systems, 30(3), 119-133.

Bellotti, F., Berta, R., De Gloria, A., Lavagnino, E., Antonaci, A., Dagnino, F. M., \& Ott, M. (2013). A gamified short course for promoting entrepreneurship among ICT engineering students. Proceedings of the 2013 IEEE 13th International Conference on Advanced Learning Technologies, 31-32.

Bhattacherjee, A., Perols, J., \& Sanford, C. (2008). Information technology continuance: A theoretic extension and empirical test. Journal of Computer Information Systems, 49(1), $17-26$.

Bosse, Y., \& Gerosa, M. A. (2017). Difficulties of programming learning from the point of view of students and instructors. IEEE Latin America Transactions, 15(11), 2191-2199.

Breen, R. L. (2006). A practical guide to focus-group research. Journal of Geography in Higher Education, 30(3), 463-475.

Bunchball, I. (2010). Gamification 101: An introduction to the use of game dynamics to influence behavior. White paper, 9.

Chen, P., Kuo, R., Chang, M., \& Heh, J.-S. (2009). Designing a trading card game as educational reward system to improve students' learning motivations. In Transactions on Edutainment III (pp. 116-128): Springer.

Combefis, S., Bersnevicius, G., \& Dagiene, V. (2016). Learning programming through games and contests: Overview, characterisation and discussion. International Olympiad in Informatics, 39-60.

de Sousa Borges, S., Durelli, V. H., Reis, H. M., \& Isotani, S. (2014). A systematic mapping on gamification applied to education. Proceedings of the 29th Annual ACM Symposium on Applied Computing, 216-222.

Dollar, N. J., \& Merrigan, G. M. (2002). Ethnographic practices in group communication research. In L. R. Frey (Ed.), New directions in group communication (pp. 59-78). Thousand Oaks, CA: Sage Publications.

El-Masri, M., Tarhini, A., Hassouna, M., \& Elyas, T. (2015). A design science approach to gamify education: From games to platforms. Proceedings of the European Conference on Information Systems, 1-10.

El Tantawi, M., Sadaf, S., \& AlHumaid, J. (2018). Using gamification to develop academic writing skills in dental undergraduate students. European Journal of Dental Education, $22(1), 15-22$.

Ferro, L. S., Walz, S. P., \& Greuter, S. (2014). Gamicards-an alternative method for paperprototyping the design of gamified systems. Proceedings of the 13th International Conference on Entertainment Computing, 11-18. 
Fotaris, P., Mastoras, T., Leinfellner, R., \& Rosunally, Y. (2015). From hiscore to high marks: Empirical study of teaching programming through gamification. Proceedings of the European Conference on Games Based Learning, pp. 1-9.

Fotaris, P., Mastoras, T., Leinfellner, R., \& Rosunally, Y. (2016). Climbing up the leaderboard: An empirical study of applying gamification techniques to a computer programming class. Electronic Journal of e-Learning, 14(2), 94-110.

Gebremichael, D. (2016). An evaluation of gamification to assess students' learning on their understanding of first year computer science programming module. (M.Sc. in Computing - Advanced Software Development), Dublin Institute of Technology.

Gilboy, M. B., Heinerichs, S., \& Pazzaglia, G. (2015). Enhancing student engagement using the flipped classroom. Journal of Nutrition Education and Behavior, 47(1), 109-114.

González, C., \& Area, M. (2013). Breaking the rules: Gamification of learning and educational materials. Proceedings of the $2^{\text {nd }}$ International Workshop on Interaction Design in Educational Environments, 47 - 53.

Hamari, J., Koivisto, J., \& Sarsa, H. (2014). Does gamification work?--A literature review of empirical studies on gamification. Proceedings of the 47th Hawaii International Conference on System Sciences, 3025-3034.

Hamari, J., Shernoff, D. J., Rowe, E., Coller, B., Asbell-Clarke, J., \& Edwards, T. (2016). Challenging games help students learn: An empirical study on engagement, flow and immersion in game-based learning. Computers in Human Behavior, 54(1), 170-179.

Hanus, M. D., \& Fox, J. (2015). Assessing the effects of gamification in the classroom: A longitudinal study on intrinsic motivation, social comparison, satisfaction, effort, and academic performance. Computers \& Education, 80, 152-161.

Hsu, S. H., Chang, J.-W., \& Lee, C.-C. (2013). Designing attractive gamification features for collaborative storytelling websites. Cyberpsychology, Behavior, and Social Networking, $16(6), 428-435$.

Ibanez, M., Di Serio, A., \& Delgado Kloos, C. (2014). Gamification for engaging computer science students in learning activities: A case study. IEEE Transactions on Learning Technologies, 7(3), 291 - 301.

Jang, Y., \& Ryu, S. (2011). Exploring game experiences and game leadership in massively multiplayer online role playing games. British Journal of Educational Technology, 42(4), 616-623.

Johnson, R. B. (1997). Examining the validity structure of qualitative research. Education, $118(2), 282-292$.

Kanbul, S., \& Ozdamli, F. (2018). Effects of the gamification supported flipped classroom model on the attitudes and opinions regarding game-coding education. International Journal of Emerging Technologies in Learning, 13(1), 109-123. 
Kankanhalli, A., Taher, M., Cavusoglu, H., \& Kim, S. H. (2012). Gamification: A new paradigm for online user engagement. Proceedings of the 33rd International Conference on Information Systems, 1-10.

Kim, S. (2013). Effects of the gamified class in engineering education environments. Journal of Convergence Information Technology, 8(13), 253-260.

Kim, J. T., \& Lee, W.-H. (2012). Dynamical model for gamification: Optimization of four primary factors of learning games for educational effectiveness. In Computer Applications for Graphics, Grid Computing, and Industrial Environment (pp. 24-32). Berlin, Germany: Springer.

Koivisto, J., \& Hamari, J. (2014). Demographic differences in perceived benefits from gamification. Computers in Human Behavior, 35, 179-188.

Koohang, A., Paliszkiewicz, J., Klein, D., \& Nord, J. H. (2016). The importance of active learning elements in the design of online courses. Online Journal of Applied Knowledge Management, 4(2), 17-28.

Krause, M., Mogalle, M., Pohl, H., \& Williams, J. J. (2015). A playful game changer: Fostering student retention in online education with social gamification. Proceedings of the 2nd ACM Conference on Learning@Scale, 95-102.

Lee, M.-C. (2010). Explaining and predicting users' continuance intention toward e-learning: An extension of the expectation-confirmation model. Computers \& Education, 54(2), 506516.

Li, C., Dong, Z., Untch, R. H., \& Chasteen, M. (2013). Engaging computer science students through gamification in an online social network based collaborative learning environment. International Journal of Information and Education Technology, 3(1), 7277.

Liyanagunawardena, T. R., Lundqvist, K. O., Micallef, L., \& Williams, S. A. (2014). Teaching programming to beginners in a massive open online course. Proceedings of the 2014 Open Education Research: Building Communities of Open Practice, 1-7

Iosup, A., \& Epema, D. H. (2014). An experience report on using gamification in technical higher education. Proceedings of the ACM Special Interest Group on Computer Science Education, 27-32.

Marshall, B., Cardon, P., \& Godin, J. (2014). A study of project-based learning in an introductory MIS course. Issues in Information Systems, 15(2), 24-30.

Mediani, H. S., Nurhidayah, I., Mardhiyah, A., \& Panigoro, R. (2017). Indonesian mothers' needs and concerns about having a thalassemic child and its treatment: An exploratory qualitative study. International Journal of Nursing \& Care, 1(2), 1-7.

Nevin, C. R., Westfall, A. O., Rodriguez, J. M., Dempsey, D. M., Cherrington, A., Roy, B., .. . Willig, J. H. (2014). Gamification as a tool for enhancing graduate medical education. Postgraduate Medical Journal, 90(1070), 685-693. 
O'Donovan, S., Gain, J., \& Marais, P. (2013). A case study in the gamification of a universitylevel games development course. Proceedings of the South African Institute for Computer Scientists and Information Technologists Conference, 242-251.

Özmen, B., \& Altun, A. (2014). Undergraduate students' experiences in programming: Difficulties and obstacles. Turkish Online Journal of Qualitative Inquiry, 5(3), 1-27.

Qu, W.-Q., Zhao, Y.-F., Wang, M., \& Liu, B.-Q. (2014). Research on teaching gamification of software engineering. Proceedings of the 9th International Conference on Computer Science and Education, 855-860.

Rich Jr, J. D., Colon, A. N., Mines, D., \& Jivers, K. L. (2014). Creating learner-centered assessment strategies for promoting greater student retention and class participation. Frontiers in Psychology, 5, 595. Available at https://www.ncbi.nlm.nih.gov/pmc/articles/ PMC4063236/

Robinson, D., \& Bellotti, V. (2013). A preliminary taxonomy of gamification elements for varying anticipated commitment. Proceedings of the ACM CHI 2013 Workshop on Designing Gamification: Creating Gameful and Playful Experiences, 1-6.

Schäfer, A., Holz, J., Leonhardt, T., Schroeder, U., Brauner, P., \& Ziefle, M. (2013). From boring to scoring-a collaborative serious game for learning and practicing mathematical logic for computer science education. Computer Science Education, 23(2), 87-111.

Schultz, D., Duffield, S., Rasmussen, S. C., \& Wageman, J. (2014). Effects of the flipped classroom model on student performance for advanced placement high school chemistry students. Journal of Chemical Education, 91(9), 1334-1339.

Sepehr, S., \& Head, M. (2013). Competition as an element of gamification for learning: an exploratory longitudinal investigation. Proceedings of the 1st International Conference on Gameful Design, Research, and Applications, 2-9.

Simões, J., Redondo, R. D., \& Vilas, A. F. (2013). A social gamification framework for a K-6 learning platform. Computers in Human Behavior, 29(2), 345-353.

Singsungnoen, K., \& Piriyasurawong, P. (2016). The design of a prototype of collaborative learning for creative thinking of junior programmer. International Journal of Applied Computer Technology and Information Systems, 6(1), 11-15.

Snipes, W., Nair, A. R., \& Murphy-Hill, E. (2014). Experiences gamifying developer adoption of practices and tools. Proceedings of the 36th International Conference on Software Engineering, 105-114.

Tao, J., \& Li, Z. (2012). A case study on computerized take-home testing: Benefits and pitfalls. International Journal of Technology in Teaching \& Learning, 8(1), 33-43.

Thamvichai, R., \& Supanakorn-Davila, S. (2012). A pilot study: Motivating students to engage in programming using game-like instruction. Proceedings of the 2012 North Midwest Section Conference on Active Learning in Engineering Education, 18-22. 
Thiebes, S., Lins, S., \& Basten, D. (2014). Gamifying information systems-a synthesis of gamification mechanics and dynamics. Proceedings of the European Conference on Information Systems, 1-17.

Tomaselli, F., Sanchez, O., \& Brown, S. (2015). How to engage users through gamification: the Prevalent effects of playing and mastering over competing. Proceedings of the International Conference on Information Systems, 1-16.

Villagrasa, S., \& Duran, J. (2013). Gamification for learning 3D computer graphics arts. Proceedings of the 1st International Conference on Technological Ecosystem for Enhancing Multiculturality, 429-433.

Vos, N., Van Der Meijden, H., \& Denessen, E. (2011). Effects of constructing versus playing an educational game on student motivation and deep learning strategy use. Computers \& Education, 56(1), 127-137.

Yang, Y., Asaad, Y., \& Dwivedi, Y. (2017). Examining the impact of gamification on intention of engagement and brand attitude in the marketing context. Computers in human behavior.

Yurov, K. M., Beasley, S. W., Kwak, M., \& Floyd, K. S. (2014). An initial study of educational game applications supporting the STEM education in K-12 systems. Online Journal of Applied Knowledge Management, 2(1), 169-179.

Zichermann, G., \& Linder, J. (2010). Game-based marketing: Inspire customer loyalty through rewards, challenges, and contests. Hoboken, NJ: John Wiley \& Sons.

\section{Author's Biography}

Mathupayas Thongmak Assist. Prof. Dr. Mathupayas Thongmak was born and grew up in Bangkok, Thailand. She received the Bachelor of Business Adminstration (2nd honor degree) from Thammasat Business School, Thammasat University. She received the Master Degree in Computer Science field from the Faculty of Engineering, Chulalongkorn University. In 2008, she received her doctorate in Computer Engineering from the Faculty of Engineering, Chulalongkorn University. She joined Thammasat Business School as a lecturer of Management Information Systems Department for almost 14 years. She presented papers in international conferences and published papers in international journals, both in Management Information Systems and Software Engineering fields. 